\title{
Correction: Plakophilin 1 enhances MYC translation, promoting squamous cell lung cancer
}

\author{
Joel Martin-Padron • Laura Boyero · Maria Isabel Rodriguez • Alvaro Andrades • Inés Díaz-Cano • Paola Peinado • \\ Carlos Baliñas-Gavira · Juan Carlos Alvarez-Perez • Isabel F. Coira · María Esther Fárez-Vidal • Pedro P. Medina
}

Published online: 13 January 2020

(c) The Author(s), under exclusive licence to Springer Nature Limited 2020

\section{Correction to: Oncogene}

https://doi.org/10.1038/s41388-019-1129-3

Following publication of this Article the Authors noted that the Acknowledgements, Funding and Author Contribution sections were incomplete. The complete, revised texts are provided for all sections below:

\section{Acknowledgments}

We thank the PhD program in Biochemistry and Molecular Biology of the University of Granada and also Montse Sanchez-Céspedes for the critical read of the paper.

\section{Funding}

JM-P and LB were supported by fellowships from Fundación Anticancer San Francisco Javier y Santa Cándida/ UGR. AA was supported by a PhD FPU fellowship (FPU17/00067). PP was supported by a PhD "La Caixa Foundation" LCF/BQ/DE15/10360019 Fellowship. IFC was supported by a PhD FPI-fellowship (BES-2013064596). JCA-P is supported by a Marie Sklodowska Curie action (H2020-MSCA-IF-2018). CB and MIR were supported by Consejería de Sanidad de la Junta de Andalucía (P1-0245-2017). MEF-V was supported by PAIDI program. Group BIO309. Junta de Andalucía, and
Instituto de Salud Carlos III-Fondo de Investigación Sanitaria PI10/00198. PPM laboratory is funded by the Ministry of Economy of Spain (SAF2015-67919-R), Junta de Andalucía (P12-BIO-1655, PAIDI CTS-993), Francisco Cobos Foundation, FERO foundation, International Association for the study of lung cancer (IASLC) and Fundación Científica de la Asociación Española Contra el Cáncer (Lab AECC-2018). The funders had no role in study design, data collection and analysis, decision to publish, or preparation of the paper. The funders had no role in study design, data collection and analysis, decision to publish, or preparation of the manuscript.

\section{Author contributions}

JM-P, LB, MIR, PP, ID-C, CB, IFC, JCA-P performed and validated the experimental data. AA performed most of bioinformatics and statistical analysis. PPM. and EF-V wrote the paper, reviewed and edited the manuscript and provided conceptualization, validation, supervision, expertise and feedback. MEF-V and PPM participated in the funding acquisition and project administration.

The HTML and PDF versions of the Article have been updated.

These authors contributed equally: Joel Martin-Padron, Laura Boyero

The original article can be found online at https://doi.org/10.1038/ s41388-019-1129-3. 